\title{
Decreased gastric emptying and gastrointestinal and intestinal transits of liquid after complete spinal cord transection in awake rats
}

F. de-A.A. Gondim, J.R.V. da-Graça,

G.R. de-O liveira, M.C.V. Rêgo,

R.B.M. Gondim and F.H. Rola
Departamento de Fisiologia e Farmacologia, Faculdade de Medicina, Universidade Federal do Ceará, Fortaleza, CE, Brasil

\section{Correspondence \\ F.H. Rola \\ Laboratório Escola \\ Prof. Luiz Capelo \\ Departamento de Fisiologia e \\ Farmacologia, UFC \\ Rua Coronel Nunes de Melo, 1127 \\ 60430-270 Fortaleza, CE \\ Brasil \\ Fax: +55-85-243-9333 \\ E-mail: meno@ufc.br \\ Part of a Master's thesis presented by F. de-A.A. Gondim to the Departamento de Fisiologia e \\ Farmacologia, UFC, Fortaleza, CE. \\ This work was presented at the \\ 8th European Symposium on \\ Gastrointestinal M otility, \\ Copenhagen, Denmark, 1996, and \\ reported in abstract form \\ (Neurogastroenterology and \\ Motility, 8: 167). Research \\ supported by CAPES, CNPq, \\ UFC and UNIMED.}

Received October 10, 1996

Accepted September 8, 1998

\section{Abstract}

We studied the effect of complete spinal cord transection (SCT) on gastric emptying (GE) and on gastrointestinal (GI) and intestinal transits of liquid in awake rats using the phenol red method. Male Wistar rats $(\mathrm{N}=65)$ weighing 180-200 g were fasted for $24 \mathrm{~h}$ and complete SCT was performed between $\mathrm{C}_{7}$ and $\mathrm{T}_{1}$ vertebrae after a careful midline dorsal incision. GE and GI and intestinal transits were measured $15 \mathrm{~min}, 6 \mathrm{~h}$ or $24 \mathrm{~h}$ after recovery from anesthesia. A test meal $(0.5 \mathrm{mg} / \mathrm{ml}$ phenol red in $5 \%$ glucose solution $)$ was administered intragastrically $(1.5 \mathrm{ml})$ and the animals were sacrificed by an $i v$ thiopental overdose $10 \mathrm{~min}$ later to evaluate GE and GI transit. For intestinal transit measurements, $1 \mathrm{ml}$ of the test meal was administered into the proximal duodenum through a cannula inserted into a gastric fistula. GE was inhibited $(\mathrm{P}<0.05)$ by $34.3,23.4$ and $22.7 \%$, respectively, at $15 \mathrm{~min}, 6 \mathrm{~h}$ and $24 \mathrm{~h}$ after SCT. GI transit was inhibited $(\mathrm{P}<0.05)$ by $42.5,19.8$ and $18.4 \%$, respectively, at $15 \mathrm{~min}, 6 \mathrm{~h}$ and 24 $\mathrm{h}$ after SCT. Intestinal transit was also inhibited $(\mathrm{P}<0.05)$ by $48.8,47.2$ and $40.1 \%$, respectively, at $15 \mathrm{~min}, 6 \mathrm{~h}$ and $24 \mathrm{~h}$ after SCT. Mean arterial pressure was significantly decreased $(\mathrm{P}<0.05)$ by $48.5,46.8$ and $41.5 \%$, respectively, at $15 \mathrm{~min}, 6 \mathrm{~h}$ and $24 \mathrm{~h}$ after SCT. In summary, our report describes a decreased GE and GI and intestinal transits in awake rats within the first $24 \mathrm{~h}$ after high SCT.

\section{Key words}

- Gastric emptying

- Gastrointestinal motility

- Gastrointestinal transit

- Intestinal transit

- Rats

- Spinal cord transection

......................
Spinal cord injury (SCI) determines severe disturbances in autoregulatory mechanisms. Gastrointestinal (GI) complications, previously underestimated, are becoming evident after the decrease in mortality resulting from the improvement in postinjury care and have been reported to account for $10 \%$ of fatalities in SCI patients (1).

Delayed large bowel transit (2) and co- lon/anorectum functional alterations (3) have been reported. Reduced motility of the distal colon has also been demonstrated in rats (4). However, there are few and conflicting studies (in humans or experimental animals) reporting disturbances in upper GI tract motility (5-9). The effect of SCI on gastric emptying (GE) is controversial, since delayed GE in humans has been reported (5-7) but is also 
questioned $(8,9)$.

One of the major problems in human protocols is the time elapsed between SCI and the beginning of the studies (varying from a few months to decades), as well as the different patterns (complete or partial) and mechanisms of SCI induction. Thus, the aim of the present study was to investigate the disturbances in GE and GI and intestinal transits of liquid after a standard complete high spinal cord transection (SCT) in awake rats (Part of this work has been published in abstract form (10)).

Experiments were performed on 65 male Wistar rats weighing 180-220 g. All surgical procedures and animal treatments were conducted in accordance with the "Guide for the Care and Use of Laboratory Animals", DHEW Publication No. (NIH) 85-23, Bethesda, MD. The animals were fasted for 24 $\mathrm{h}$ but water was allowed ad libitum. They were anesthetized with ether and treated with atropine $(0.5 \mathrm{mg} / \mathrm{kg}, i p)$, which appears to be essential to avoid respiratory complications in SCT animals (11). Two polyethylene cannulas (PE 50) filled with heparin solution $(500 \mathrm{U} / \mathrm{ml})$ were then inserted into the left external jugular vein for sacrifice and into the right carotid artery for mean arterial pressure (MAP) measurements. The distal end of the cannulas was tunneled subcutaneously to the scapular region and secured to the back with sutures after a dorsal skin incision.

After these initial procedures, the seventh cervical $\left(\mathrm{C}_{7}\right)$ and first thoracic $\left(\mathrm{T}_{1}\right)$ vertebrae were carefully exposed via a midline dorsal incision and SCT was performed using a microscissor. Bleeding was minimal and usually stopped in 10-15 s. The completeness of SCT was confirmed by careful inspection of the lesion with the aid of a $10 \mathrm{X}$ lens coupled to an optic light. This procedure resulted in the removal of a 1-2 mm segment of the spinal cord. Complete transection was confirmed in all cases. Immediately after SCT, the rats were allowed to recover on a warm pad and closely monitored for signs of respiratory or circulatory distress. Usually, the rats were awake and mobile (using their forelimbs) $15 \mathrm{~min}$ after surgery. We considered healthy spinal rats those that exhibited grooming and exploratory behavior when removed from their cages, according to Osborn et al. (11).

SCT and sham-operated animals submitted to GE, GI or intestinal transit measurements 15 min after recovery from anesthesia did not receive the atropine pretreatment to avoid the immediate interference of atropine with gut motility.

For GE and GI transit measurements $24 \mathrm{~h}$ after recovery from anesthesia, a separate group of animals was submitted to additional surgical procedures. Because SCT impairs micturition reflexes (11), we catheterized the bladder with a (PE 50) catheter, through a small lateral abdominal incision before SCT. The bladder catheter was connected to a finger glove to avoid environmental exposure and to measure urinary volume. Animals from this group received an ip injection of procaine penicillin $(30,000 \mathrm{IU} /$ $\mathrm{kg}$, bid).

Sham-operated animals were prepared as the SCT animals, including the same duration of anesthesia, length of surgical procedure, atropine administration (except for GE, GI and intestinal transit measurements 15 min after recovery from anesthesia) and laminectomy, according to Meshkinpour et al. (4). The time elapsed between recovery from anesthesia and GE, GI and intestinal transit measurements was also $15 \mathrm{~min}, 6 \mathrm{~h}$ or $24 \mathrm{~h}$, and thus three different sham groups were prepared.

The methodology for GE measurement was a modification of Scarpignato's technique (12). First, $1.5 \mathrm{ml}$ of the test meal containing a non-absorbable marker $(0.5 \mathrm{mg} /$ $\mathrm{ml}$ phenol red in $5 \%$ glucose solution) was administered by gavage into the stomach through a stainless steel tube that was removed immediately after delivering the so- 
lution. The animals were sacrificed by an iv thiopental overdose $10 \mathrm{~min}$ after test meal administration, the stomach was exposed by laparotomy, quickly clamped at the pylorus and cardia ends and then removed.

Stomachs were placed in $100 \mathrm{ml}$ of $0.1 \mathrm{~N}$ $\mathrm{NaOH}$, cut into small pieces and homogenized for $30 \mathrm{~s}$. The suspension was allowed to settle for $20 \mathrm{~min}$ at room temperature and $10 \mathrm{ml}$ of the supernatant was centrifuged for $10 \mathrm{~min}(2800 \mathrm{rpm})$. Proteins in $5 \mathrm{ml}$ of homogenate were precipitated with $0.5 \mathrm{ml}$ of trichloroacetic acid $(20 \%, \mathrm{w}: \mathrm{v})$, centrifuged for $20 \mathrm{~min}(2800 \mathrm{rpm})$ and $4 \mathrm{ml}$ of $0.5 \mathrm{~N}$ $\mathrm{NaOH}$ was added to $3 \mathrm{ml}$ of the supernatant. The absorbance of the sample was read at $560 \mathrm{~nm}$ by spectrophotometry. Gastric volume was assumed to be equal to the volume (in $\mathrm{ml}$ ) of $0.1 \mathrm{~N} \mathrm{NaOH}$ displaced after stomach immersion. The percent gastric emptying $(\% \mathrm{GE})$ for each rat was calculated according to the following formula: $\% \mathrm{GE}=1$ amount of phenol red recovered from test stomach x 100/average amount of phenol red recovered from standard stomachs.

Rats sacrificed immediately after test meal administration were used to establish the standard stomachs $(100 \%$ phenol red in the stomach).

In order to exclude a possible modification of gastric acid secretory pattern induced by SCT, which could interfere with the measurement of the actual GE (12-14), we administered ranitidine $(10 \mathrm{mg} / \mathrm{kg}$, ip, Glaxo, Rio de Janeiro, Brazil) $30 \mathrm{~min}$ before the test meal to 2 separate groups of animals: the sham-operated and the SCT animals at $6 \mathrm{~h}$ after recovery from anesthesia.

GI transit measurements were performed according to a modification of the method of Megens et al. (15). After quickly clamping the pylorus and cardia ends to perform GE measurements, the small intestine - from the gastroduodenal junction to the cecum was carefully removed and lightly stretched along a meterstick on a flat table top. Tiny scissor cuts were then performed along the small intestine and $0.1 \mathrm{~N} \mathrm{NaOH}$ solution was spilled over the luminal leaking phenol red solution to visualize the farthest point reached by the head of the test meal (i.e., pink color). The small intestine length and the distance travelled by the marker along the small intestine were measured. Since the intestines were all of quite similar length (mean $110.3 \pm 4.1 \mathrm{~cm}$ ), the GI transit index was defined as distance the marker traveled/ total length of intestine $\mathrm{x} 100$.

For intestinal transit measurements of SCT or sham-operated animals, we used a modification of Summer's technique (16). The animals were anesthetized with ether, a midline abdominal incision was performed and a fistula was created in the gastric fundus. A polyethylene cannula (PE 50) was introduced into the fistula and then inserted and fixed into the duodenum, $2 \mathrm{~cm}$ after the pylorus. The gastric fistula was closed by a transverse suture (6.0 silk) which also kept the cannula positioned in the duodenum. The distal end of the cannula was subcutaneously tunneled to the scapular region, where it was secured to the back of the animals with sutures after a dorsal skin incision. Intestinal transit was measured $24 \mathrm{~h}$ after cannula insertion and 10 min after administration of 1 $\mathrm{ml}$ of the test meal into the duodenum. The same technique used for GI transit measurement was used for intestinal transit determination, i.e., distance the marker traveled/ total length of intestine $x 100$. SCT or shamoperation was also performed $15 \mathrm{~min}$, and 6 $\mathrm{h}$ or $24 \mathrm{~h}$ before intestinal transit measurements.

Mean arterial pressure (MAP) in $\mathrm{mmHg}$ was recorded every $5 \mathrm{~min}$ from $10 \mathrm{~min}$ before SCT to $15 \mathrm{~min}$ after recovery from anesthesia. For this purpose, the catheter placed in the right carotid artery was connected to a mercury manometer.

Results are reported as means \pm SEM. Descriptive statistics were applied to each group of experiments. One-way analysis of variance (ANOVA), the Student-Newman- 
Keuls test (to compare the GE and GI transit) and ANOVA on Ranks (to compare the gastric volumes) were then used to compare the differences between the various groups. Differences were considered significant at $\mathrm{P}<0.05$.

Figure 1 (A, B and C) shows that GE and GI and intestinal transits of liquid were significantly decreased $15 \mathrm{~min}, 6 \mathrm{~h}$ and $24 \mathrm{~h}$ after recovery from anesthesia in SCT animals $(\mathrm{P}<0.05)$.

GE decreased from $37.9 \pm 3.5(\mathrm{~N}=4)$ to $24.9 \pm 4 \%(\mathrm{~N}=4)(\mathrm{P}<0.05) 15$ min after recovery from anesthesia, from $40.9 \pm 4(\mathrm{~N}$ $=5)$ to $31.3 \pm 2.2 \%(\mathrm{~N}=5)(\mathrm{P}<0.05) 6 \mathrm{~h}$ after recovery from anesthesia and from $39.7 \pm$ $3.2(\mathrm{~N}=5)$ to $30.7 \pm 4.2 \%(\mathrm{~N}=5)(\mathrm{P}<0.05)$ $24 \mathrm{~h}$ after SCT.

Figure 1 - Gastric emptying and gastrointestinal and intestinal transits of a liquid meal in awake rats. Under ethereal anesthesia the animals were randomly submitted to laminectomy (shamoperation) or to complete spinal cord transection (SCT) between $\mathrm{C}_{7}$ and $\mathrm{T}_{1}$ vertebrae. GE and $\mathrm{Gl}$ and intestinal transit measurements were performed $15 \mathrm{~min}$, $6 \mathrm{~h}$ or $24 \mathrm{~h}$ after recovery from anesthesia. After receiving a test meal $(0.5 \mathrm{mg} / \mathrm{ml}$ of phenol red in $5 \%$ glucose solution), the animals were sacrificed $10 \mathrm{~min}$ later. $A$ and $B, G E$ and $G$ I transit percentages, respectively, in sham-operated or in SCT animals after $1.5 \mathrm{ml}$ test meal gavage. $\mathrm{C}$, Small intestinal transit percentages in sham-operated or in SCT animals after intraduodenal administration of $1.0 \mathrm{ml}$ of the test meal. $* P<0.05$, SCT vs paired sham-operated group (StudentNewman-Keuls test).
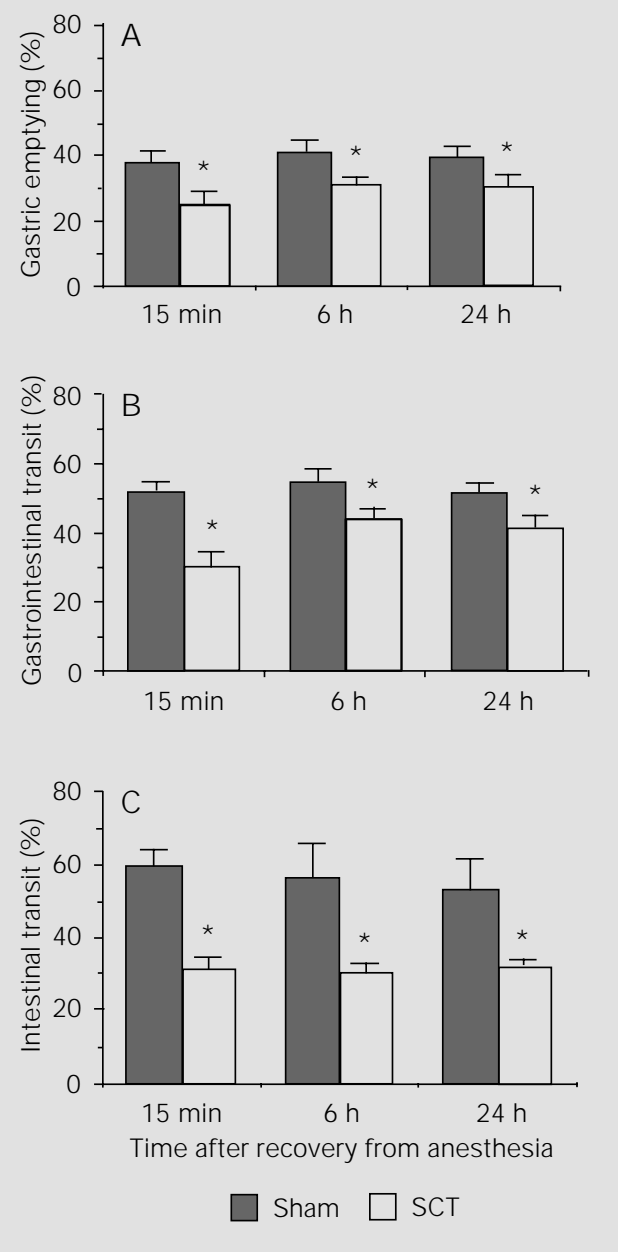

GI transit was also decreased $(\mathrm{P}<0.05)$ from $52 \pm 2.7$ to $29.9 \pm 4.9 \%$, from $55 \pm 3.8$ to $44.1 \pm 3.1 \%$ and from $51.5 \pm 3.3$ to $42.1 \pm$ $3.3 \%$, respectively, at $15 \mathrm{~min}$, and $6 \mathrm{~h}$ and 24 $\mathrm{h}$ after recovery from anesthesia.

Intestinal transit was decreased $(\mathrm{P}<0.05)$ from $60.2 \pm 3.7(\mathrm{~N}=4)$ to $30.8 \pm 3.9 \%(\mathrm{~N}=$ 4), from $57.1 \pm 8.7(\mathrm{~N}=4)$ to $30.1 \pm 2.7 \%(\mathrm{~N}$ $=4)$ and from $53.6 \pm 8.2(\mathrm{~N}=5)$ to $32.1 \pm$ $1.8 \%(\mathrm{~N}=5)$, respectively, at $15 \mathrm{~min}, 6 \mathrm{~h}$ and $24 \mathrm{~h}$ after recovery from anesthesia.

We observed a trend for increased gastric volumes in animals submitted to the SCT. However, there was no statistical difference when comparing the mean gastric volume $(2.4 \pm 0.3 \mathrm{ml})$ in sham-operated with $3.1 \pm$ 0.3 and $3.4 \pm 0.2 \mathrm{ml}$, respectively, for 6 and $24 \mathrm{~h} \mathrm{SCT}$ animals.

In animals pretreated with ranitidine, the SCT also decreased significantly $(\mathrm{P}<0.05)$ the GE $(29.3 \pm 2.8 \%, \mathrm{~N}=4$ vs $38.9 \pm 3.0 \%$, $\mathrm{N}=5$ in sham-operated) and the GI transit $(39.3 \pm 3.8 \%, \mathrm{~N}=4$ vs $53.5 \pm 3.7 \%, \mathrm{~N}=5$ in sham-operated).

SCT also decreased significantly $(\mathrm{P}<0.05)$ MAP values from $111.7 \pm 3.3 \mathrm{mmHg}$ to 60.6 $\pm 3.8,62.6 \pm 2.8$ and $68.8 \pm 2.2 \mathrm{mmHg}$, respectively, at $15 \mathrm{~min}, 6 \mathrm{~h}$ and $24 \mathrm{~h}$ after recovery from anesthesia.

To the best of our knowledge, this is the first report describing a delay of GE and GI and intestinal transits of liquid after standard SCT between $\mathrm{C}_{7}$ and $\mathrm{T}_{1}$ vertebrae in experimental animals. In fact, only few and conflicting data about this subject are available: a delayed GE in SCI patients has been reported (5-7) but subsequently questioned $(8,9)$. This controversy may be explained by the variation in the time elapsed between SCI and the beginning of the studies and the different patterns and mechanisms of SCI induction. These problems are minimized in experimental animals, since the pattern of the lesions can be precise and easily reproducible.

The effect described here appears to be related to gut motility rather than to modifi- 
cations in gastric secretory pattern - which could interfere with the measurement of actual GE (12) - since GE and GI transit delays were also observed after ranitidine administration and no major differences in gastric volume were verified when we compared the different SCT groups.

The GI motility changes verified within the first day after SCT could be related to the sudden changes in autonomic nervous system activity elicited by SCT. This spinal shock phase is not fully understood yet, despite more than a century of intense work in clinical and laboratory settings (14). However, the spinal systems appear to be active minutes after transection in rats following the spinal shock phase and autonomic hyperreflexia is completely established within 1 day after SCT (11).

In the present experiments, we also observed a significant decrease in MAP values which is in agreement with a previous study (17). It should be stressed that persistent arterial hypotension verified up to 10 days after high SCT in rats (17) has led to the notion that SCT decreases the activity of all sympathetic nerves. However, some investigators have reported that such high transection may even increase the sympathetic activity of some organs (16-18), suggesting different degrees of supraspinal excitatory dependence. Colon or urinary distention can also elicit sudden and exaggerated sympathetic reflexes, resulting in arterial hypertension (16). This is a very controversial subject, since there is conflicting evidence in the literature about the effect of SCT on sympathetic activity. Recent studies on awake rats have suggested that the spinal cord cannot generate significant sympathetic activity after SCT (13). This contrasts with other reports of enhanced or unchanged peripheral sympathetic activity of some organs, i.e., heart, kidney and spleen (17). Another plausible explanation for our results is the facilitation of the enterogastric (19) and intestinointestinal reflexes (20), which could occur after the acute split of spinal centers from supraspinal modulation.

In summary, our results indicate that GE and GI and intestinal transits of liquid were inhibited after complete SCT between $\mathrm{C}_{7}$ and $\mathrm{T}_{1}$ vertebrae. Additional studies are necessary to determine the mechanisms involved in this phenomenon.

\section{Acknowledgments}

We thank Dr. Armenio Aguiar dos Santos for his comments and help in revising the manuscript.

\section{References}

1. Miller LS, Staas WE \& Herbison GJ (1978). Abdominal problems in patients with spinal cord lesions. Archives of Physical Medicine and Rehabilitation, 56: 405-408.

2. Menardo G, Bausano G, Corazziari E, Fazio A, Marangi A, Genta V \& Marenco G (1987). Large-bowel transit in paraplegic patients. Disease of the Colon and Rectum, 30: 924-928.

3. Longo WE, Ballantyne GB \& Modlin IM (1989). The colon, anorectum, and spinal patient. Disease of the Colon and Rectum, 32: 261-267.

4. Meshkinpour $\mathrm{H}$, Harmon $\mathrm{D}$, Thompson $\mathrm{R}$ \& Yu J (1985). Effects of thoracic spinal cord transection on colonic motor activity in rats. Paraplegia, 23: 272-276.

5. Fealey RD, Szurszewski J H, Merritt J L \& DiMagno EP (1984). Effect of traumatic spinal cord transection on human upper gastrointestinal motility and gastric emptying. Gastroenterology, 87: 69-75.

6. Segal J L, Milne N, Brunemann SR \& Lyons KP (1987). Metoclopramide-induced normalization of impaired gastric emptying in spinal cord injury. American J ournal of Gastroenterology, 82: 11431148.

7. Segal $J L$, Milne $N \&$ Brunemann $S R$ (1995). Gastric emptying is impaired in patients with spinal cord injury. American J ournal of Gastroenterology, 90: 466-470.

8. Rajendran SK, Reiser J R, Bauman W, Zhang RL, Gordon SK \& Korsten MA (1992). Gastrointestinal transit after spinal cord injury: effect of cisapride. American J ournal of Gastroenterology, 87: 16141617.

9. Zhang RL, Chayes Z, Korsten MA \& Bauman WA (1994). Gastric emptying rates to liquid and solid meals appear to be unaffected by spinal cord injury. American J ournal of Gastroenterology, 89: 1856-1858.

10. Gondim F de AA, Graça J RV, Oliveira GR, 
Rego MCV, Gondim RBM, Dantas RP, Cavalcante DIM, Santiago AT \& Rola FH (1996). Complete spinal cord transection decreases gastric emptying and intestinal propulsion in awake rats. Neurogastroenterology and Motility, 8: 167 (Abstract).

11. Osborm J W, Taylor RF \& Schramm LP (1990). Chronic cervical spinal cord injury and autonomic hyperreflexia in rats. American J ournal of Physiology, 258: R169-R174.

12. Scarpignato C, Capovilla T \& Bertaccini $G$ (1980). Action of caerulein on gastric emptying of the conscious rat. Archives Internationales de Pharmacodynamie et de Therapie, 246: 286-293.

13. Trostel K \& Osborn J W (1994). Does the spinal cord generate functionally signifi- cant sympathetic activity in the awake rat? American J ournal of Physiology, 266: R1102-R1110.

14. Atkinson PP \& Atkinson J LD (1996). Spinal shock. Mayo Clinic Proceedings, 71: 384-389.

15. Megens AA, Canters LL, Awouters FH \& Niemegeers CJ (1990). Normalization of small intestinal propulsion with loperamide-like antidiarrheals in rats. European J ournal of Pharmacology, 178: 357-364.

16. Summers RW, Thomas TH \& Osborne J W (1970). Effects of drugs, ileal obstruction, and irradiation on rat gastrointestinal propulsion. Gastroenterology, 59: 731739.

17. Osborn JW, Taylor RF \& Schramm LP (1989). Determinants of arterial pressure after chronic spinal transection in rats. American J ournal of Physiology, 256: R666-R673.

18. Trostel KA, Kata SA \& Osborn J W (1991). Functional evidence for sympathetic nerve activity in conscious cervical rats. American J ournal of Physiology, 261: R434-R441.

19. Schapiro H \& Woodward ER (1955). Inhibition of gastric motility by acid in the duodenum. J ournal of Applied Physiology, 8: 21 .

20. J ohansson $B$, J onsson $O \&$ Ljung $B$ (1968). Tonic supraspinal mechanisms influencing the intestino-intestinal inhibitory reflex. Acta Physiologica Scandinavica, 72: 200-204. 